UNIVERSIDADE FEDERAL DO ESTADO DO RIO DE JANEIRO - UNIRIO
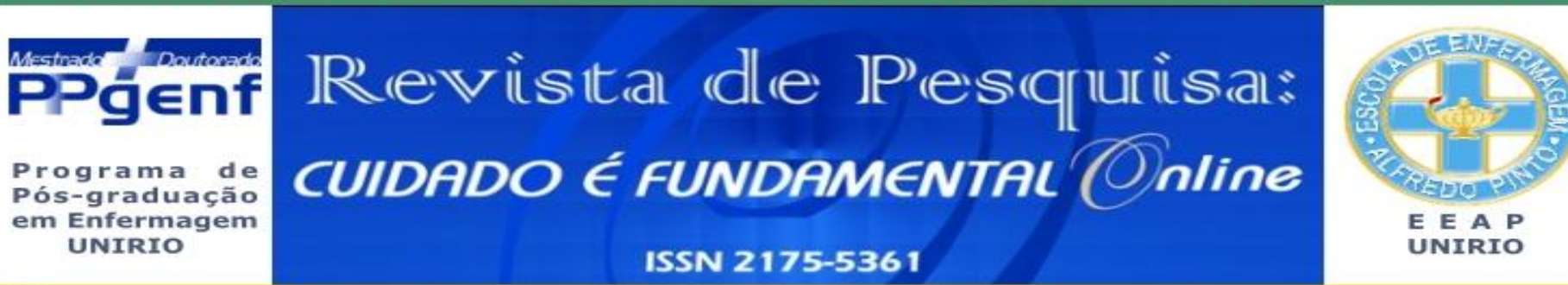

Ministério da Educação

PESQUISA

\title{
DISCLOSING ACTIVES ARQUETIPOS ON THE WOMAN EXISTENCE ON THE HOSPITAL DELIVERY: SOCIOPOETIC STUDY
}

REVELANDO ARQUÉTIPOS ATIVOS NA VIVÊNCIA DE MULHERES NO PARTO HOSPITALAR: ESTUDO SOCIOPOÉTICO REVELANDO ARQUETIPOS ACTIVOS NA VIVÊNCIA DE MUJERES EN LA PARTRICIÓN HOSPITALARIA: ESTUDIO
SOCIOPOETICO

Ana Paula Alves Salgado ${ }^{1}$, Iraci dos Santos ${ }^{2}$, Jane Márcia Progianti ${ }^{3}$

\begin{abstract}
Objective: Toidentified the active archetypes that involved the women's behavior during hospital delivery through of the woman imagination dimensions connected in the woman way of life in this modality delivery. Method: Sociopoetic reaserch was developed with a researcher group modeling a mother goddess as a technique to for data production, which took place in a maternity hospital at Rio de Janeiro in 2009. Results: They would be during delivery revealing the archetypes personified by the grecian goddesses Artemis, Demeter, Persephone and Hestia, the Virgin Mary and the egyptian goddess of destruction, Sekhmet. The perception about the meaning of these archetypes showed their strengths, needs and desires of the: liberty and delivery, loneliness and solitude, to feel relating with her son, passionate donation and with self-esteem. Conclusion: This study alarm to sensitive boarding in the holistic care of the human being, to amplify actions privileging subjectivities and eccentricity. Descriptores: Obstetrical nursing, Women's health, Hospital delivery, Care.
\end{abstract}

\section{RESUMO}

Objetivo: Identificar os arquétipos ativos que influenciam o comportamento feminino no parto hospitalar, através da dimensão imaginativa da mulher referente à sua vivência dessa modalidade de parto. Método: Pesquisa sociopoética desenvolvida com um grupo pesquisador formado por oito puérperas, que aplicaram a técnica de modelagem das deusas, em ambulatório de puericultura do Rio de Janeiro, em 2009. Resultados: As puérperas significaram suas modelagens, revelando-se as deusas gregas: Ártemis, Deméter, Perséfone e Héstia, a Virgem Maria e a deusa egípcia da destruição, Seckhmet. Percebeu-se que as autoras dessas modelagens mostraram suas potências, necessidades e desejos de: liberdade e autonomia no parto, solidão e isolamento, sentir a ligação com seu filho, doação amorosa, sentir-se poderosa e com autoestima. Conclusão: 0 estudo alertou para a abordagem sensível no cuidado integral das pessoas, visando ampliar ações privilegiando subjetividades e singularidades. Descritores: Enfermagem obstétrica, Saúde da mulher, Parto hospitalar, Cuidado.

\section{RESUMEN}

Objetivo: Identificar los arquetipos activos que influencian en el comportamiento feminino durante el parto hospitalario, mediante el dimensión imaginativa de la mujer referente a su vivencia de esa modalidad de parto. Método: Investigación sociopoética desarrollada con el grupo investigador compuesto por ocho madres que han modelado la diosa madre como técnica de producción de datos, en una maternidad en Río de Janeiro-Brasil, en 2009. Resultados: Los arquetipos personificados por las diosas griegas Artemisa, Deméter, Perséfone y Hestia, la Virgen María y la diosa egipcia de la destrucción Seckhmet. Las investigadoras demuestraron sus poténcias, necesidades y deseos de: liberdad e autonomía en el parto, solitud y aislamiento, sentir la ligación con su hijo, donación amorosa, sentir-se poderosa y con auto-estima. Conclusión: El estudio alarma para el abordaje sensible en el cuidado lleno de las perssonas, haya vista ampliar acciones privilegiando subjectividades y singularidades. Descriptores: Enfermería obstétrica, Salud de la mujer, Parto hospitalario, Cuidado.

\footnotetext{
1 Enfermeira. Especialista em Neonatologia. Mestre em Enfermagem pelo Programa de Pós-Graduação em Enfermagem da Universidade do Estado do Rio de Janeiro- UERJ - Brasil. Professora da Faculdade de Enfermagem- UERJ. E-mail: anapsalg@yahoo.com.br. ${ }^{2}$ Enfermeira. Doutora em Enfermagem. Professora Titular do Departamento de Fundamentos em Enfermagem e do Programa de Pós-Graduação em Enfermagem da UERJ. Pesquisadora do CNPq. E-mail: iraci.s@terra.com.br. Enfermeira Obstétrica. Doutora em Enfermagem. Professora Adjunta do Departamento de Enfermagem Materno-Infantil e do Programa de Pós-Graduação em Enfermagem da Faculdade de Enfermagem da UERJ. E-mail: jmprogi@uol.com.br. Artigo elaborado a partir da Dissertação de intitulada "A dimensão cultural mítico-simbólica de mulheres no parto vaginal hospitalar:desafios para o cuidar de enfermeiras obstétricas”. Programa de Pós-Graduação em Enfermagem da UERJ - Brasil, 2010. Bolsista da Coordenação de Aperfeiçoamento de Pessoal de Nível Superior.
} 


\section{INTRODUÇÃO}

As mulheres agem conduzidas por duas forças poderosas: os arquétipos do inconsciente coletivo e os esteriótipos da cultura. ${ }^{1}$ Essas forças estão supostamente presentes no nível de realidade Mundus Imaginalis. No inconsciente, os arquétipos são as estruturas básicas da imaginação, que ficam inativados à espera de serem re-imaginados para tomar parte ativa no consciente. Na maternidade a mulher vivencia um período de transformações intenso que se caracteriza também como um período de atualizações arquetípicas. Ainda situa-se neste nível de realidade a dimensão cultural míticosimbólica, na qual repousam os grandes mitos e símbolos sobre gestação, parto e nascimento.

Conhecer os arquétipos predominantes das mulheres que parem, no contexto hospitalar e saber identificá-los ajudará as enfermeiras obstétricas a compreender o comportamento das mesmas durante 0 parto. ${ }^{2}$ Nesse sentido, contemplar a abordagem da dimensão espiritual das parturientes através do cuidado espiritual possibilita a ampliação das ações de saúde para as dimensões subjetivas e singulares dos clientes e seus familiares e contribui para a superação dos padrões de cuidar, pautados na competência técnico-científica, na direção do modelo de assistência humanizado. ${ }^{3-5,6}$

Assim, formula-se o problema de pesquisa: quais são os arquétipos ativos na mulher que pare no hospital e como estes influenciam o seu comportamento durante o parto vaginal?

Este artigo é um recorte de dissertação de mestrado, defendida no Rio de Janeiro, em 2010, que teve como objetivo identificar os arquétipos que influenciam o comportamento feminino no parto hospitalar através da dimensão imaginativa da mulher referente á sua vivência dessa modalidade de parto.

\section{METODOLOGIA}

0 imaginário da mulher foi privilegiado através da dimensão cultural mítico-simbólica, utilizando-se o método sociopoético para a produção e análise de dados. ${ }^{7}$ Este se fundamenta em Pedagogia do oprimido de Paulo Freire, Escuta mito-poética, sensível de René Barbier, Teatro do oprimido de Augusto Boal e Análise institucional de René Lourau, e se desenvolve desde uma postura dialógica.

Os princípios filosóficos da sociopoética afirmam a instituição do dispositivo analítico grupo pesquisador (GP), o reconhecimento dos saberes das culturas de resistência e oprimidas; o corpo como fonte de conhecimento; a utilização de práticas artísticas e de sensibilidade durante a pesquisa; a valorização do sentido humano e espiritual dos conteúdos dos saberes e, dos conhecimentos produzidos pelos sujeitos de pesquisa. $^{7-8}$

Ressalta-se, que a simultaneidade da aplicação dos fundamentos teóricos e dos princípios filosóficos desse método, no desenvolvimento do GP, possibilitou a construção coletiva de um corpo de conhecimentos específicos para a enfermagem obstétrica.

\section{Campo, sujeitos e estratégias para o desenvolvimento da pesquisa}

Foi escolhida uma instituição de saúde no município do Rio de Janeiro-Brasil, que atende a mulher e a criança, além de dispor de espaço físico adequado ao desenvolvimento de atividades grupais. Para constituir o GP foram oferecidas 20 vagas no curso Cuidando da mãe e do bebê, divulgado através de convites distribuídos no Ambulatório de Puericultura da referida instituição, além da divulgação verbal pela pesquisadora após a aprovação pelo Comitê de 
Salgado APA, Santos I, Progianti JM.

Ética em Pesquisa dessa instituição (Protocolo $n^{\circ}$ 0002/09).

$\mathrm{Na}$ sala de espera das consultas de puericultura, as puérperas foram convidadas a participar do dispositivo grupo pesquisador que configurou, ao mesmo tempo, um curso e uma pesquisa. Neste curso realizou-se a seleção dos sujeitos, utilizando um formulário contendo os critérios de inclusão na pesquisa: estar no período do décimo ao quadragésimo quinto dias de pósparto vaginal e hospitalar, ser multípara, com partos de baixo ou alto risco, concordar em participar da pesquisa após conhecer seus objetivos, riscos e vantagens, assinando o termo de consentimento livre e esclarecido (TCLE).

Foram excluídas as mulheres: primíparas, puérperas que sofreram aborto, com idade inferior a dezoito anos, as que tiveram seus partos sob anestesia geral ou que tiveram bebês com malformações incompatíveis com a vida; e não vivenciaram 0 parto normal no ambiente hospitalar.

O GP foi composto por oito mulheres que atenderam aos critérios propostos, assinaram 0 TCLE, autorizaram a filmagem, gravação em MP3, a publicação das modelagens de figuras durante dos encontros realizados e se cientificaram do termo de confidencialidade, do programa de encontros do GP (oficinas sociopoéticas) com as pesquisadoras e respectivos dados de contato. 0 espaço físico para a realização das atividades do GP foi uma sala adequada para o desenvolvimento de trabalhos grupais na referida instituição, que autorizou a utilização do seu nome no trabalho, assim como o acesso às puérperas atendidas na puericultura.

Os encontros do grupo aconteceram semanalmente, com duração de duas horas por encontro/oficina, num total de oito fases específicas do GP totalizando 16 horas de atividades grupais. A produção de dados realizou-
Disclosing actives arquetipos... se de janeiro a abril de 2009 e a análise dos dados de janeiro a junho deste ano.

No intuito de assumir uma postura de abertura ao novo, ao imprevisível, e seguir um rigor quanto à argumentação ao empregar uma linguagem adequada aos dados da pesquisa, o método de análise foi escolhido enquanto os dados foram sendo produzidos pelo GP. Neste artigo, utilizou-se a análise de conteúdo delimitando-se categorias temáticas segundo o estudo filosófico da sociopoética. ${ }^{7-9}$

Tal estudo considera a interpretação/experimentação dos dados produzidos a partir dos grandes temas da história filosófica, na cultura ocidental. Sobreleva-se, que na dinâmica do GP importam as heterogeneidades, a multiplicação de diferenças produzidas e não as identidades. A atenção é voltada ao movimento que cada sujeito realiza no grupo sobre o seu território, ao mesmo tempo em que o mesmo entra em contato com o território do outro, construindo novas configurações. ${ }^{7}$

Nesta pesquisa, foram desenvolvidas as seguintes técnicas: dinâmicas de sensibilidade, incentivadoras do imaginário e relaxamento corporal, no início das oito fases do GP. Pois através da ampliação da consciência corporal pela função psíquica sensorial, essas técnicas visam à paz no corpo, com o afastamento das tensões corporais geradas pelo dia-a-dia e estabelecimento da atenção plena; exercício de centramento, que por ser contemplativo e meditativo, ele aproxima o ser humano de sua essência, conduzindo à compreensão de que se é mais do que pensamentos passageiros, emoções e desejos que, levam à diminuição da freqüência cerebral, com consequente redução dos controles conscientes pelo pensamento racional.

Esse exercício cria uma percepção de autorelatividade que pode ser pensada como um lugar interior, um lugar de calma dentro de si, que possibilita percepção de integração, unificação e 
Salgado APA, Santos I, Progianti JM.

foco; ${ }^{5}$ e a dança negociada com as componentes do GP.

Escolheu-se como técnica para produção de dados a vivência de lugares geomíticos e a modelagem de arquétipos segundo os elementos da natureza (terra, ar, fogo e água). Ressalta-se, que a expressão em argila proporciona a exploração das sensações táteis e sua verbalização. A argila é por si mesma o símbolo do nascimento, de vida, de morte. É repleta de significações ancestrais e sensoriais, além de ser a matéria pela qual a imaginação se entrega às metamorfoses, permitindo transformar para conhecer. $^{10}$

Após o relaxamento corporal foi lido um texto sobre a mitologia grega e as características das deusas gregas Héstia, Perséfone, Demeter, Afrodite, Atena, Hera e Ártemis. Após a leitura, foi apresentada a questão orientadora da pesquisa: Se você tivesse sido uma deusa no parto, qual delas teria sido se o seu parto fosse... a terra, o ar, a água e o fogo?

Após um minuto de olhos fechados pensando na pergunta, as puérperas modelaram com argila a deusa que teriam sido no parto nas condições supostas pela pergunta orientadora e em seguida apresentaram para o grupo sua obra explicando seus significados. No encontro seguinte ocorreu a contra-análise da modelagem da deusa.

\section{RESULTADOS E DISCUSSÃO DOS DADOS}

\section{Modelando a deusa mãe: estudo sociopoético filosófico}

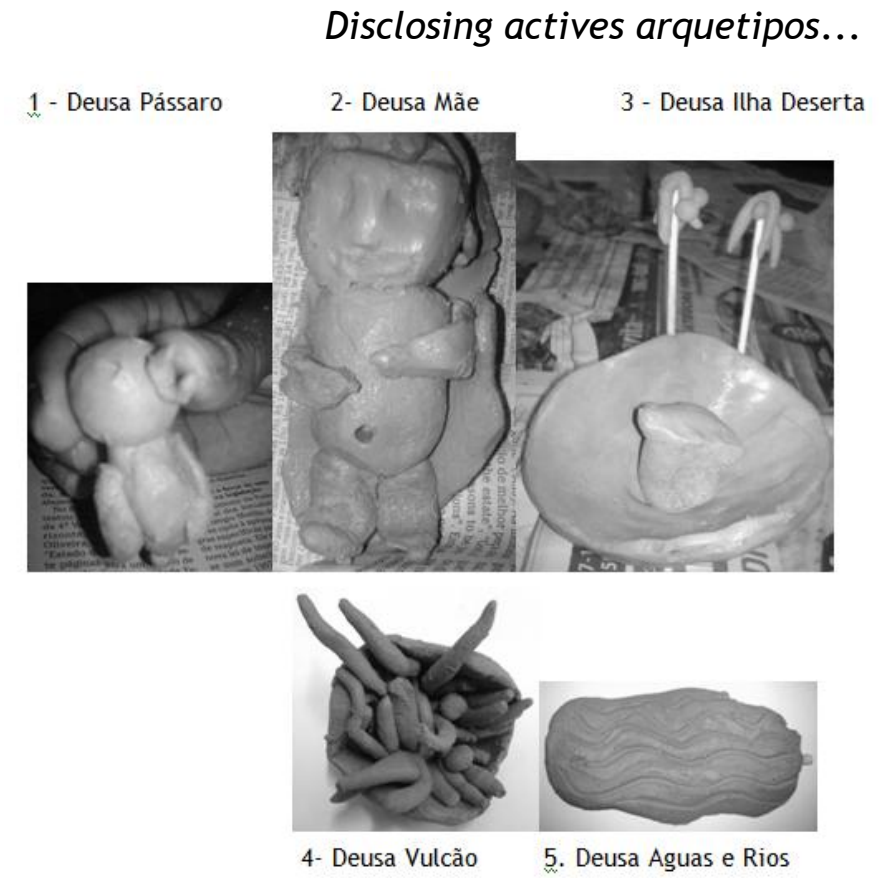

Figura 1 - Modelagem das deusas mães pelo grupo pesquisador. Rio de Janeiro, 2010.

Associando sua vivência do parto no hospital à modelagem da deusa, o grupo pesquisador (GP) imaginou quais deusas seriam se o parto fosse a terra, a água, o ar, o fogo, apresentando sua dimensão imaginativa das seguintes deusas: pássaro, mãe, ilha deserta, vulcão, das águas e dos rios. (Ver figura 1).

Constatou-se a inexistência de modelagens dos arquétipos de deuses gregos. Entretanto as deusas (pássaro, mãe, ilha deserta,vulcão e águas e rios) modeladas pelas puérperas, membros do grupo pesquisador compreendem características comportamentais de ambos os gêneros. Fato que permitiu, que o GP expressasse sua multiplicidade comportamental. Desse modo, são descritas as categorias temáticas referentes a cada arquétipo ativo identificado. As falas das componentes do GP foram identificadas pelo nome da deusa que imaginaram na sua modelagem.

\section{A deusa pássaro: transcendendo á dor para a liberdade}

Eu seria um pássaro porque conseguiria sair, fugir da dor a hora que eu quisesse. Seria livre. (Deusa pássaro)

No imaginário sobre o parto vaginal e hospitalar, as mulheres imaginaram que seriam 
Salgado APA, Santos I, Progianti JM.

deusas que possuíssem asas que, simbolicamente, representam a liberdade, a possibilidade de locomoção para se afastar da dor, fugir da mesma ou eliminá-la quando quisessem. Para isso, modelaram as argilas criando animais alados, como o pássaro, que têm a liberdade de ir e vir e a capacidade de eliminar a dor encontrada em Ártemis, deusa da caça e da lua.

A deusa pássaro (ver figura 1) revelou através da característica liberdade o arquétipo da deusa grega Ártemis. Aqui, considerando-se a vivência dos lugares geomíticos, se o parto fosse o ar, as componentes do GP seriam a deusa pássaro.

\section{A Deusa Mãe perfeita e lutadora}

Eu seria uma deusa mãe, aquela que nasceu pra ser mãe, a que seria uma mãe perfeita, tipo uma leoa sabe?!. (Deusa mãe)

A amorosidade relacionada aos filhos e à maternidade foi uma qualidade da deusa evidenciada na dimensão imaginativa do GP. Essa qualidade pode ser encontrada mais fortemente em Deméter, a deusa dos grãos, que personifica o arquétipo da mãe e o instinto maternal. A deusa era descrita como uma mulher muito bonita, de cabelos louros, vestida com uma túnica azul e retratada como uma majestosa figura sentada igual á modelagem apresentada na figura 1 .

\section{Uma Ilha Deserta para contemplação da maternidade}

Eu seria uma ilha deserta. Ficaria sozinha lá com meu filho, só eu e ele. (Deusa Ilha Deserta)

A modelagem da deusa ilha deserta (ver figura 1) se assemelha a uma mandala, que é um símbolo de integridade ou de totalidade. 0 objeto no centro da modelagem pode simbolizar o ponto central no interior da psique da sua autora, a sua chama acesa, o fogo sagrado de Héstia, com o R. pesq.: cuid. fundam. online 2013. jan./mar. 5(1):3323-32
Disclosing actives arquetipos... qual todas as coisas estão relacionadas e são ordenadas e é, em si mesmo, a fonte de sua energia. É deste centro, floresce o aprendizado da mulher em Héstia. É de lá que ela se relaciona e aprende a conhecer seu filho.

\section{Como um vulcão poderoso, queimando e transbordante de dor}

Eu seria um vulcão muito poderoso, muito quente, que causa muita dor, a dor do mármore do inferno, transbordando de dor. (Deusa vulcão)

No imaginário das parturientes o fogo simboliza a dor. Diferentemente do fogo contemplativo de Héstia, aquele que aquece e ilumina e faz de uma casa um lar, o fogo imaginado pelo GP provoca uma dor quase insuportável para o ser humano, a dor do mármore do inferno.

Buscando outras referências, encontrou-se a deusa egípcia Seckhmet, uma deusa muito mais antiga, de mais de 3000 A C, a deusa da ira transformadora. Assim como Kali-Ma, a deusa hindu da destruição, Seckhmet toma a frente quando é chegado o momento de agir diante daquilo que é inaceitável. Com a cabeça de leão e corpo de mulher, a imagem metade humana, metade animal da deusa Seckhmet foi esculpida com basalto escuro ou granito negro, ambos são rochas de magma de vulcão solidificado. Se o parto fosse o fogo, as componentes do GP seriam a deusa vulcão e a deusa caldeirão (ver Figura 1).

Tal significado é semelhante à percepção da dor mencionada pelas co-pesquisadoras nas modelagens da Deusa Vulcão e Deusa Caldeirão que são influenciadas pelo arquétipo de Sekhmet.

\section{Um Rio passando e levando a dor da minha vida}

Eu seria um rio. Um rio onde a água pudesse levar devagarinho a dor embora. Não ficaria com aquela dor acumulada. Ela ia indo embora 
Salgado APA, Santos I, Progianti JM.

devagarinho pra ficar suportável. (Deusa das águas e dos rios)

A autora da modelagem associou a dor á sua experiência do parto. Ao invés do desejo de fugir da dor ou eliminá-la, ela se transformou, em seu imaginário, na deusa das águas e dos rios, para ter a habilidade de escoar vagarosamente a dor acumulada, com a finalidade de atingir os limites do suportável. Vê-se que ela acolheu a dor em sua experiência rejeitando apenas o excesso, a dor insuportável.

$\mathrm{Na}$ modelagem (ver figura 1), observa-se a haste por debaixo do leito do rio com a sua extremidade à direita. O que simboliza o eixo vertebral de sustentação, o equilíbrio dessa mulher ao ser influenciada pelo arquétipo de Perséfone em sua versão mais madura, ao invés da inocente Coré. Se o parto fosse a água, a autora da modelagem seria a Deusa das Águas e dos Rios.

A prática artística de modelagem em argila das deusas gregas associando-as aos elementos da natureza, junto à vivência de lugares geomíticos estimulou o imaginário das puérperas sobre seus traços comportamentais mais marcantes em relação à vivência do parto. Tal fato permitiu a identificação de arquétipos personificados na figura mitológica das deusas gregas do Olimpo, já descritas na seção de resultados. ${ }^{1,11}$ Ressalta-se, que as deusas pássaro, mãe, ilha deserta, vulcão, águas e rios, modeladas pelas puérperas, coincidentemente, possuem características comportamentais semelhantes às observadas nas mulheres contemporâneas.

Acredita-se, tal como os primeiros filósofos gregos, que muito das imagens produzidas provêm da provocação dos 4 elementos materiais (água, terra, fogo e ar).

O que justificou a adoção da modelagem em argila associada ao significado desses elementos.

Sendo assim, a modelagem em argila que é feita de terra favorece a expressão de conteúdos
Disclosing actives arquetipos...

inconscientes. ${ }^{10} \mathrm{~A}$ modalidade de expressão em argila proporciona a exploração das sensações táteis e sua verbalização por seu autor. A argila é por si mesma o símbolo do nascimento, de vida, de morte. Ela é repleta de significações ancestrais e sensoriais, além de ser a matéria, pela qual a imaginação se entrega às metamorfoses, permitindo transformar para conhecer. ${ }^{12}$

Interessante é notar a modelagem da deusa pássaro por um membro do GP. Recorda-se que, esta simboliza a vida selvagem, cruzando florestas, os descampados, as montanhas e campinas, com seu bando de ninfas e cães de caça. Ela cultivava com toda a sua força o amor intenso pela liberdade, independência e autonomia pelos quais luta com uma agressividade instintiva. Diferentemente de todas as outras deusas gregas, apenas Ártemis usava uma túnica curta, veste que facilitava seu desenvolvimento nas matas.

Neste caso infere-se que o GP composto por puérperas revelaram seu anseio por liberdade e autonomia gerar e gerir o seu parto. Tal inferência corrobora a história de Ártemis, que nasceu de sua mãe Leto num parto sem dor. Logo que nasceu, ajudou sua mãe no parto mais difícil da mitologia grega, o de seu irmão Apolo. Grávida de Apolo, Leto sofreu dores atrozes durante nove dias e nove noites quando, enfim, com a ajuda de Ártemis como parteira, Apolo nasceu. Por esse motivo, Ártemis era considerada a deusa do nascimento, orava aos pés das parturientes para que dessem à luz sem dor. ${ }^{1}$

Há que se reforçar ser o ar, elemento da natureza que, é parte do fundamento da imaginação material; é um convite à viagem, ao vôo e, ao mesmo tempo, é a imagem da evasão, da flutuação e da mobilidade, condições que parecem refletir o devaneio das puérperas imaginando seu momento do parto. ${ }^{13}$

A realização do arquétipo como mãe é de extrema importância para uma mulher sob a 
Salgado APA, Santos I, Progianti JM.

influência do arquétipo personificado por Deméter, como bem retratada na imagem de mãe e filho na modelagem. A maternidade é o sentido da vida para a mulher Deméter. Por personificar o instinto materno ela tem afiado o senso de proteção de sua cria, exatamente como um coração de leoa, conforme a fala da autora da modelagem. ${ }^{1-2,7-8,10-13}$

Além da imagem maternal (ver figura 1) observa-se, que o cabelo da deusa Demeter, modelada pelo GP, prolonga-se pelas costas até o chão, lembrando o manto que cobre o corpo da Virgem Maria da igreja católica e da deusa chinesa Kuan Yin adorada há mais de mil anos na China, Coréia e Japão. ${ }^{11}$ Ambas são reverenciadas como deusas da compaixão, que embora não sejam deusas em suas tradições teológicas, na prática, são reverenciadas como santas ou divinas. Ambas são bondosas, empáticas, solidárias, sempre possuindo uma resposta pronta às necessidades de alguém, qualidades que as mulheres, quando já não fazem parte de suas personalidades, passam a desenvolver com a maternidade. ${ }^{1}$

0 isolamento e a introspecção são características marcantes do arquétipo personificado pela deusa grega Héstia, a deusa da lareira e do templo. Héstia foi a única deusa a não tomar parte dos conflitos de sua época, pois não era vista envolvida em guerras e disputas, tampouco aventurando-se em romances. Essa deusa de vestes sóbrias representa a segurança pessoal, a felicidade e o dever sagrado da hospitalidade. $^{1}$

Héstia é a deusa da centralização interior, sua consciência é focada para a interioridade, necessária na meditação, na contemplação e na prece. Seu modo de aprender é olhar para o interior e sentir intuitivamente o que está se passando, assim, a deusa tem um desapego natural e busca a solidão e o isolamento para encontrar a tranqüilidade, assim como a mãe, sujeito desta pesquisa, procura a ilha deserta,

\section{Disclosing actives arquetipos...}

para ficar isolada com seu filho, pelos dois coqueiros. ${ }^{11}$

$\mathrm{Na}$ linguagem da vivência dos lugares geomíticos, se o parto fosse a terra, a copesquisadora seria uma deusa ilha deserta, que resiste emersa apesar do mar. Pois essa Deusa traz em si a força do elemento da natureza terra, com sua plasticidade e resistência, penetração, intimidade e um repouso dinâmico, assim como o arquétipo de Héstia. ${ }^{2,7,12-13}$

Referente à deusa Seckhmet, ressalta-se que a dor muito intensa está freqüentemente relacionada ao ambiente e clima emocional desfavoráveis. ${ }^{14}$ Assim, não sendo encontrado, na mitologia grega, uma deusa simbolizando o fogo destruidor, ampliou-se a pesquisa bibliográfica para demais deusas de outras mitologias, conforme recomenda a sociopoética, cujos referenciais interdisciplinares, geralmente surgem a posteriori e a partir dos conhecimentos das culturas de resistência e dominadas. ${ }^{7}$

Nas mulheres Seckhmet, seus corações explodem em fúria pelo mal que ameaça subjugar e destruir o que para elas é sagrado. Nenhuma deusa se compara a ela em termos de poder. Essa deusa faz o papel destruidor da grande mãe em sua função tripla como criadora, sustentadora e destruidora. 1:140

Foi retratada como a deusa que expelia fogo contra os inimigos do faraó, expressando a ira e a selvageria da leoa protetora. Era invocada para colocar o equilíbrio no mundo, quando nenhuma outra divindade, inclusive as mais poderosas divindades masculinas não 0 conseguiam.

No mais famoso mito $A$ destruição da espécie humana, Sekchmet era possuída pela agressão e ferocidade contra o mal, de forma que ninguém conseguia contê-la, nem ela mesma. Para isso, Rá, deus do sol e seu pai, a enganou induzindo-a a beber uma poção de coloração semelhante ao sangue que alterou sua mente 
Salgado APA, Santos I, Progianti JM. restaurando sua sanidade. ${ }^{1: 128}$ Pode-se comparar a poção que Rá fez para ela com as anestesias utilizadas nas mulheres durante o parto.

A anestesia serve, então, como uma camisa de força química que silencia o arquétipo fazendo com que a mulher fique mais dócil, auxiliando-a recuperar o autocontrole para que assim possa saber que decisão tomar, uma vez que esteja tomada pela raiva. ${ }^{1}$

0 arquétipo de Seckhmet é eficaz quando equilibrado pela sabedoria, caso contrário, pode se tornar destrutivo para as mulheres. Com sabedoria, as mulheres não se deixam explodir em ataques de fúria, nem agem à mercê de seus impulsos, mas sim, canalizam a ira para um compromisso com a mudança, para a determinação de encontrarem o melhor caminho, para a transformação. ${ }^{1}$

No caso do parto, para que haja essa sabedoria a mulher deve reconhecer a capacidade de sentir dor como um sinal de boa saúde, deve reconhecer o sentido pessoal da dor direcionandoa para uma ação objetiva para superar o desafio imediato. No entanto, a medicalização fez a mulher não identificar a dor como um aspecto de sua saúde, reduzindo-a a um problema técnico, um sinal diagnóstico. ${ }^{15}$

O fogo é o elemento da natureza que impele à mudança, assim como Sekhmet dá um basta no que já não mais pode suportar, sinalizando para a mulher a necessidade da mudança. ${ }^{13}$

O efeito devastador do fogo de Sekhmet continuará sendo sentido pelas mulheres que não conseguem tomar uma atitude que direcione sua energia emocional no processo do parto. Um estudo recente sobre mulheres que vivenciaram o parto vaginal mostra um significado que as mulheres dão à dor no parto: sofrimento inútil vazio de sentido e caracterizado como uma dor de extrema intensidade, as quais as mulheres não podem controlar ou suportar. ${ }^{15-16}$
Disclosing actives arquetipos...

No mesmo estudo, os pesquisadores concluíram que o encorajamento para a vivência do parto com liberdade, diminuiu a percepção de dor nas mulheres. ${ }^{16}$ Nos casos de dor durante o processo de parto, as enfermeiras obstétricas devem se lembrar de propor, à parturiente, estratégias não-farmacológicas para o alívio da dor, como massagens lombo-sacrais, exercícios respiratórios, relaxamento muscular e banho de chuveiro, que são muito eficazes, principalmente, se utilizadas de forma combinada e criteriosa. ${ }^{17}$

Pois como uma tecnologia não invasiva de cuidado de enfermagem obstétrica, as estratégias não farmacológicas para o alívio da dor são um saber estruturado, aplicado com uma intencionalidade e uma justificativa e que produz um resultado. ${ }^{18}$

A deusa das águas e dos rios foi identificada como o arquétipo personificado pela deusa grega Perséfone em sua fase madura. Essa deusa comeu as sementes de romã oferecidas por Hades no mundo inferior integrando, para si, a experiência que teve durante o tempo em que ficou seqüestrada. ${ }^{1}$

Quanto à deusa das águas e dos rios, a água é o elemento que simboliza a pureza, as forças humanas mais escondidas e simples, menos participativas e mais íntimas bem como as forças, a timidez e a profundidade de Perséfone. ${ }^{13}$

\section{CONSIDERAÇÕES FINAIS}

Considerando a prática artística de pesquisa Modelagem das deusas mães, foi descrita a dimensão imaginativa do grupo pesquisador, que revelou quais deusas suas componentes seriam no momento do parto hospitalar. Assim, foram identificados os arquétipos ativos personificados pelas deusas gregas Ártemis, Deméter, Perséfone e Héstia, a Virgem Maria da igreja católica e a deusa egípcia da destruição Seckhmet. 
Salgado APA, Santos I, Progianti JM.

Nessa dimensão imaginativa, o comportamento das mulheres, sujeitos da pesquisa, também foi desvelado, mostrando que a mulher Ártemis possui forte anseio pela liberdade e necessitam cuidados de enfermagem que respeitem sua singularidade e seus saberes próprios, conduzindo-a, assim, ao alcance de sua autonomia e conseqüente preservação de sua liberdade.

Por outro lado, o arquétipo Perséfone foi identificado, já na sua fase madura, momento no qual aceitou a experiência de viver em sua inteireza, tornando-se mais sábia. Este conhecimento, aqui produzido alerta que, mulheres como Perséfone necessitam ser constantemente estimuladas no processo criativo de parir. Isso porque se desenvolvem melhor em atividades que envolvam parceria, principalmente, de saberes.

Os arquétipos ativos simbolizados na deusa amorosa, Deméter e a Virgem Maria da igreja católica foram identificados nas modelagens revelando a intensidade pelo amor materno dos componentes do GP. Nesse sentido, as enfermeiras obstétricas ao lidarem com mulheres sob a influência desses arquétipos, que precisam doar-se inteiramente ao outro, podem ajudá-las a perceber suas próprias necessidades a fim de colocá-las em prioridade. A identificação de Héstia revelou que, mulheres com esse arquétipo ativo caracterizam-se pela introspecção, necessidade de isolamento e solidão durante 0 parto. Portanto, para seu cuidado de enfermagem obstétrica, as enfermeiras ajudarão no processo do parto promovendo a privacidade de uma parturiente sob a influência dessa deusa.

Já Seckhmet foi identificada através da dor insuportável para o ser humano simbolizada pelo calor do mármore do inferno e pelo fogo do vulcão. A energia dessa deusa é a energia do basta e tem um poder destruidor. Se sua ira não for
Disclosing actives arquetipos...

direcionada para uma ação objetiva as conseqüências podem ser prejudiciais à mulher. Assim, à medida que as enfermeiras obstétricas promovem o empoderamento estimulando a autoestima e autonomia, protegem as mulheres de danos como os causados, por exemplo, pela energia destruidora do arquétipo de Seckhmet.

Podem, então, contribuir com as parturientes no sentido de suportar a própria dor impedindo-as de serem arrebatadas pelo arquétipo de alguma deusa que personifique a ira transformadora ou a destruição. Se houver a reorientação da energia da ira para ações mais objetivas e saudáveis durante o parto, as enfermeiras estarão contribuindo para reduzir os índices de cesarianas.

Conclui-se, que a prática artística Modelagem da deusa mãe proporcionou às mulheres, sujeitos da pesquisa, a reconstrução de suas histórias, lhes deu o poder de deusas. Poderosas como tais, as autoras dessas modelagens puderam mostrar além de suas potências, suas necessidades e desejos: de liberdade e autonomia no parto, de solidão e isolamento, de sentir a ligação com seu filho, de doação amorosa, de sentir-se poderosa, com autoestima.

Com as modelagens, elas puderam colocar a qualidade da dor em seu sentido pessoal. Ora a mulher se transforma em deusa para fugir da dor, ora ela se transforma em deusa para controlar a dor. Ora a dor se torna insuportável para o ser humano, ou nem tanto que não se possa deixá-la ir aos poucos. Assim, a Modelagem da deusa mãe, lhes possibilitou 0 acesso ao seu manancial simbólico para que elas pudessem reconstruir o seu mito pessoal do parto.

\section{REFERÊNCIAS}


Salgado APA, Santos I, Progianti JM.

1. Bolen JS. As deusas e a mulher madura. Arquétipos nas mulheres com mais de 50. São Paulo (SP): Triom; 2005.

2. Salgado APA, Progianti JM, Santos I dos. Dimensão mítico-simbólica de mulheres sobre o parto: estudo sociopoético. Rev enferm UFPE On Line. 2010;jan-mar. 4 (1):300-10.

3. Leão ER. Cuidar de pessoas e música. São Caetano do Sul (SP): Yendis; 2010.

4. North American Nursing Diagnosis Association. Diagnóstico de enfermagem da NANDA: definições e classificação 2003-2004. Porto Alegre: Artmed; 2005.

5. Watson J. Enfermagem pós-moderna e futura: um novo paradigma da enfermagem. Loures (PO): Lusociência; 2002.

6. Soares FS, Santos I dos. Necessidades de acolhimento de familiares de clientes internados em unidade de terapia intensiva: estudo sociopoético. EAN Rev Enferm. 2010; jan-mar. 14 (1):34-37.

7. Santos I dos, Gauthier J, Figueiredo NMA, Petit SH. Prática da pesquisa nas ciências humanas e sociais: abordagem sociopoética. São Paulo (SP): Atheneu; 2005.

8. Gauthier J. Pour une réflexion anticolonialiste sur l'autorisation noétique, spirituelle, corporelle et politique des chercheurs. Rev Enferm UERJ. 2008; jan-mar. 16:269-75.

9. Petit SH, Gauthier J, Santos I dos, Figueiredo NMA. Introduzindo a Sociopoética. In: Santos I dos, Gauthier J, Figueiredo NMA, Petit SH, organizadores. Prática de pesquisa nas ciências humanas e sociais: abordagem sociopoética. São Paulo (SP): Atheneu; 2005. p.1-39.

10. Tavares CMM. A provocação poética dos elementos materiais: novas categorias de análise na abordagem sociopoética. Rev Bras Enferm 1999; jan-mar. 52 (1):283-92.
Disclosing actives arquetipos...

11. Bolen JS. As deusas e a mulher. Nova psicologia das mulheres. $8^{\text {a }}$ ed. São Paulo (SP): Paulus; 2007.

12. Tavares CMM. O simbolismo na produção e análise de dados na pesquisa em sociopoética. In: Santos I dos, Gauthier J, Figueiredo NMA, Petit SH. Prática da pesquisa nas ciências humanas e sociais: abordagem sociopoética. São Paulo (SP): Atheneu; 2005. p. 163-73.

13. Bachelard G. O direito de sonhar. 4. ed. Rio de Janeiro (RJ): Bertrand Brasil; 1994.

14. Balaskas J. Parto ativo: guia prático para o parto natural. São Paulo (SP): Ground; 1993.

15. Macedo PO. Significando a dor no parto: expressão feminina da vivência do parto vaginal. [Dissertação]. Rio de Janeiro: Programa de Pós-Graduação em Enfermagem, Universidade do Estado do Rio de Janeiro; 2007.

16. Macedo PO, Progianti, JM, Vargens OMC, Santos I, Silva CA. Percepção da dor pela mulher no pré-parto: a influência do ambiente. Rev Enferm UERJ. 2005;jan-mar. 13 (1):306-12.

17. Davim RMB, Torres GV, Dantas JC. Efetividade de estratégias não farmacológicas no alívio da dor de parturientes no trabalho de parto. Rev Esc Enferm USP, 2009; abr-mai 43(2):438-45.

18. Torres JA, Santos I dos, Vargens OMC. Construindo uma concepção de tecnologia de cuidado de enfermagem obstétrica: estudo sociopoético. Texto Contexto Enferm 2008;out-dez 17(4): 656-64.

Recebido em: 26/04/2012

Aprovado em: 31/08/2012 